\title{
Oceanography
}

CITATION

Boxall, S. 2018. Are you a marine major or minor? Oceanography 31(1):148-149,

https://doi.org/10.5670/oceanog.2018.103.

DOI

https://doi.org/10.5670/oceanog.2018.103

COPYRIGHT

This article has been published in Oceanography, Volume 31, Number 1, a quarterly journal of The Oceanography Society. Copyright 2018 by The Oceanography Society. All rights reserved.

USAGE

Permission is granted to copy this article for use in teaching and research.

Republication, systematic reproduction, or collective redistribution of any portion of this article by photocopy machine, reposting, or other means is permitted only with the approval of The Oceanography Society. Send all correspondence to: info@tos.org or The Oceanography Society, PO Box 1931, Rockville, MD 20849-1931, USA. 


\section{Are You a Marine Major or Minor? вy $\operatorname{simon}$ Boxall}

After my last column in Oceanography in September 2017 (https://doi.org/10.5670/ oceanog.2017.305), in search of inspiration, ideas for new articles have flooded in, which, like buses, seem to always arrive in groups. Some from readers (with my thanks), and some from the fathomous depths of my own mind. On a contemporary topic, Alan Mix (TOS president) and Ellen Kappel (my long-suffering editor) suggested looking at how a wide range of undergraduate programs are building a marine science focus into their curricula. I say contemporary, as we have just seen the latest (and possibly best) offering from Sir David Attenborough in his recently aired Blue Planet II. As with many such noteworthy documentary series, the interest in studying for a degree in oceanography or marine biology has consequently seen a measurable boost as young people become inspired by oceanic adventures and the great unknown. But the benefit of programs like Blue Planet is that they also provide an elegant public platform for our science and highlight its importance in twenty-first century society, identifying issues from plastic pollution in the sea to climate change.

In an ideal world we might see a plethora of bright students electing to study marine science at the undergraduate level, but it is still a relatively small number of universities around the world that offer such degrees. Many still focus on graduate degree or research pathways. In addition, many prospective students have an interest in the ocean but perhaps do not want to major in science, nor do they have the right background for a full degree in science, or indeed want to follow a pure science or maths pathway. The last of this group will form a significant number of our graduate cohort, and so exposure to some marine science at the undergraduate level is important for future recruitment. In addition, future professionals in science, engineering, law, and politics who have some exposure to marine science will bring the core issues of the subject to the fore.

So it is simple-provide subsidiary courses or minors in marine sciences that students from a wide range of disciplines could follow and benefit from. In the distant past when I did my degree (with just three other students!), other undergraduates also took some of our marine science modules as a part of their maths, chemistry, or physics degrees, swelling numbers to over 80 in some modules. It has to be said, and with due respect to my professors of the time, while the four of us lapped up the details of advanced ocean dynamics and tidal theory, it was a touch on the dry side for the other students. The interest back then was inspired by the adventures of Jacques Cousteau aboard Calypso rather than today's David Attenborough and his Alucia. Many students taking subsidiary units were disappointed to discover that there were no field expeditions to the sun-soaked coasts of the Mediterranean, with dinner on the aft deck chatting about science over a glass of wine while barbecuing Jacques's latest discovery from the deep. There was a lot of (difficult) maths and theory to deal with first, and many never returned to the subject to reach the more hedonistic stages...

Today, students from other degree courses do take some of my own first-year modules, and they come from a wide variety of disciplines. As well as the expected geologists and environmental scientists, I have biochemists, geographers, mathematicians, engineers, and even the occasional law student. Ensuring that the a priori knowledge needed fits with such a diverse cohort can at times be challenging. I need to ensure that our oceanography major students can progress to higher levels while still making the course interesting to the others, for whom it may be their only foray into marine science. It is important to ensure there is a good mix of theory and practice, and while our teaching vessel doesn't have a barbecue and operates in the slightly cooler English Channel, it does offer an inspiring window on the subject for all students. My own school offers joint degrees with marine science as a minor with subjects like geography. However, in the UK we have yet to fully embrace the concept of a minor concentration. There are set pathways, but the option of, say, a degree in physics with a minor of your choice is still some way off.

There are two issues with this. In order to fulfill the basic needs of the major (or main degree), there are some essential units that every marine scientist, chemist, or geographer needs to cover. In the United States and many other countries, it takes at least four years to earn a bachelor's degree, but in the UK, most degrees are awarded in three years (with growing pressure from government to reduce this period to an accelerated two years). While the core material for a four-year program can still be covered and allow a student to concentrate in a minor subject area, this becomes difficult to achieve within a three-year period. In my School of Ocean and Earth Science, we have to think carefully about what unit a student can drop whenever a new unit is introduced.

The second issue-timetables-is more frustrating. As with many universities, our timetables work within our departments, which is great if students wanting to undertake units outside their own subject stay within the department. However, if the student wants a crossdepartment experience, it becomes a logistical nightmare. It is often made worse by the fact that, in many cases, the 
marine science school is remote from the university's main campus, involving a 20- or 30-minute bus journey between lectures. My school has moved departments twice and is about to undergo a new change in 2018. Twenty years ago, marine science was in the same department as environmental science and geography. This meant that a third of students in our first- and some second-year courses were from these subjects and we saw a good cross-fertilization of subjects. We then became a Faculty of Natural and Environmental Science, which strangely didn't include environmental science (hang on...it gets even stranger...). At that stage, interfaculty timetabling meant that only the most determined students from environmental science or geography could attend marine science courses. In addition, increased student numbers across the university and more units actually meant more restricted timetables and less choice, which is very much the case in other universities. We have actually gone back on options rather than forward. The good news is that we are reforming departments in 2018 and will once again encompass environmental science and geography, along with midwifery (I said it gets stranger...). I guess midwives might benefit from a first-year module in oceanography for those ever-popular water births? Nothing worse than an unexpected tsunami in the birthing pool.

There is a genuine desire for more cross-faculty units from our university hierarchy, but the reality is that a major leap across departments is difficult. This brings us to the alternative-taking examples from what is a very cool subject (we are slightly biased) and building them into other subjects. Wave theory in physics is an example where ocean waves are much more exciting than bits of string, the ocean provides an excellent applied mathematics focus for calculus, and the subject of international issues of marine resources is a very hot and contemporary item for economics and politics majors. After some level of success in trying to get examples of marine science into our school (pre-university) curriculum, we should be working in our own universities to introduce some of our subject into other university undergraduate schools, and not just in science. At Southampton, some of our staff are shared with other departments, for example, with engineering, with archeology, and with maritime law. It is often easier to timetable a member of staff than it is to timetable 150 students all doing differing pathways. In addition, for short three-year programs it does not detract from the core material needed in a particular subject.

The perfect solution? Well, there is still an issue. Persuading an academic to increase teaching load, and in another department, is never going to be easy when we are under more and more time pressure. Marine science is being introduced in science departments in other universities in the UK that don't have a tradition or track record in the field. The number of colleagues who move to join departments of biology, chemistry, geography, environmental science, and engineering is on the rise. They are not only taking their marine research into these new departments but are also building a marine focus into their teaching so that individual units now consider issues such as marine renewables, coastal defenses, sustainable marine ecosystems, and numerical ocean modeling. These subjects are part of their core teaching role, and they do provide a way of introducing some of the concepts of marine science to non-oceanographers. Having come from more traditional schools and departments of marine science, these instructors are also well placed to signpost enthusiastic students into the field at the graduate level. It all lacks one thingif a university doesn't have a fully developed marine science department, it is also unlikely to have the best component of our subject, a boat or research ship.

In the United States, Canada, and Bermuda, a growing number of summer schools open to undergraduates enable them to experience fieldwork firsthand. These programs provide training and experience that build on initial interest that may be sparked by one or two modules with a marine focus in their undergraduate programs. In Europe, although there are postgraduate summer schools, there are very few that target undergraduates. Ironically, we are very good at targeting students pre-university, but there seems to be a gap at the undergraduate level. We are about to embark on a project with the British Council in the UK to bring a group of British and German students together for a short residential course to improve their ocean literacy, with a focus on rising sea levels and plastic litter. The objective would be to build on their diverse degree programs and consider not just the science but also socioeconomic issues.

If the answer to more inclusion of marine subjects in a wide range of undergraduate programs is introducing staff with marine backgrounds, then there will be a need to increase access to the exciting facilities and opportunities at the more traditional marine science schools across the globe. Such an effort will need funding-resources do not come cheapbut the benefits to the subject should be significant in the long term. I know that Alan Mix is keen to discover more, as am I, and so following on from my previous request for topics to be covered, we would be very interested in understanding what other academics' experiences have been in introducing ocean or marine science into non-marine science programs. Please email us with your experiences, and if there is sufficient response, we will provide a follow-up article on this subject in the near future.

And if anyone can think of an oceanographic link into midwifery, I'd love to hear about it. 厄

\section{ARTICLE CITATION}

Boxall, S. 2018. Are you a marine major or minor? Oceanography 31(1):148-149, https://doi.org/10.5670/ oceanog.2018.103.

\section{AUTHOR}

Simon Boxall (srb2@noc.soton.ac.uk) is Associate Professor, Ocean and Earth Science, University of Southampton, National Oceanography Centre, Southampton, UK. 